\title{
Shiki Nagaoka: la postfotografía como estrategia bioficcional del fake*
}

\section{Dunia Gras**}

\begin{abstract}
Resumen
La obra de Mario Bellatin dialoga, generalmente, con el lenguaje visual. La llamada 'postfotografía, término empleado por el teórico de la imagen Joan Fontcuberta, subraya la importancia de las técnicas de reapropiación de materiales preexistentes, como los álbumes fotográficos familiares. En Shiki Nagaoka: una nariz de ficción (2001), Bellatin traza una biografía imaginaria, en la que cuestiona el empleo de la fotografía como supuesta imagen de verdad, al utilizarla como estrategia bioficcional para sustentar la impostura de su texto espurio o fake. Con ello se pone en cuestión el estatuto de verdad que, aparentemente, emana de las imágenes fotográficas utilizadas para construir la figura de un escritor: la coherencia sintáctica de la gramática de la representación fotográfica se revela irrelevante y subraya su esencia original de simulacro.
\end{abstract}

Palabras clave: Postfotografía, biografías imaginarias, impostura literaria.

\section{Shiki Nagaoka: postphotography as a (bio)fictional strategy for fake literature}

\begin{abstract}
The work of Mario Bellatin dialogues usually with visual language. So-called post-photography, a term introduced by the theorist Joan Fontcuberta, underlines the importance of reappropriation techniques in the recycling of existing materials, such as familiar photograph albums. In Shiki Nagaoka: una nariz de ficción (Shiki Nagaoka: a Nose for Fiction), Bellatin creates an imaginary biography in which he questions photography as an image of truth, using it as a biofictional strategy to sustain the imposture of an apocryphal or fake text. In this way he casts doubt on the statute of truth that seems to emanate from the photographs used to build a writer's image; its syntactic coherence proves irrelevant in the end, revealing its original essence as a simulacrum.
\end{abstract}

Keywords: post-photography, imaginary biographies, literary imposture.

Recibido: 26-01-2017

Aceptado: 31-03-2017

\footnotetext{
* Una primera versión de este texto fue presentada en 2004 en el congreso de la AEELH y luego revisada en el coloquio del IILI de 2005 en Poitiers. Sin embargo, no pudo publicarse debido a la dificultad técnica de reproducir las imágenes que, en un principio, la acompañaban. Agradezco a la Dra. Lorena Amaro haberme ayudado a rescatarlo y reformularlo con sus comentarios, en el seminario "La bioficción y otros horizontes literarios de la biografía”, moderado por la Dra. Anna Caballé en la Universitat de Barcelona el 18 de noviembre de 2016. Agradezco también a los motores de mi reflexión inicial, la profesora Kobayashi Keiko y las estudiantes Okamoto Kayoko y Fukuda Yumeko por su inestimable ayuda con los textos japoneses: sin ellas, estas páginas tampoco habrían sido posibles.

** Española. Doctora en Filología Hispánica por la Universitat de Barcelona. Académica de la Universitat de Barcelona, España.dunia.gras@ub.edu
} 
El canon de la literatura mexicana se nutre, considerablemente, de los márgenes. Juan José Arreola encabeza, acaso, esa literatura marginal que se convierte en central, fundamental. Y también acoge a excéntricos aún más periféricos, como es el caso del guatemalteco Augusto Monterroso o del español Max Aub. También en esta línea se inscribe la obra del escritor mexicano, de origen peruano, Mario Bellatin (México, D. F., 1960), excéntrica también en otros sentidos, y que va a ser el centro del análisis de las siguientes páginas. Sus libros han ido apareciendo en el mercado editorial en español de forma dispersa pero contundente, y las traducciones de su obra han circulado, más allá de sus fronteras lingüísticas, especialmente en francés, en menor medida en alemán e italiano y, de forma intensa, en los últimos años, en inglés ${ }^{1}$, configurándose así en un escritor de culto, con un público fiel que espera sus nuevas entregas, y que recibe cada vez mayor atención por parte de la crítica académica.

A caballo, en un principio, entre el campo literario peruano, en el que publicó Mujeres de sal (1986), en la emblemática editorial Lluvia, y el mexicano, en el que se ha consolidado, tras el impactante Salón de belleza (1994), publicado primero en la limeña Jaime Campodónico y luego en la sede mexicana de la editorial Tusquets ${ }^{2}$, ha ido emergiendo un proyecto literario arriesgado y calculado a la vez, ${ }^{3}$ que ha cruzado fronteras: tras su salto transatlántico con ese texto, se inició su reconocimiento internacional, su paso por la española Anagrama, hasta su consolidación en Alfaguara donde, además de su Obra reunida (2013), han aparecido Retrato de Mussolini con familia (2015) -de difícil clasificación, una vez más, entre el aforismo y la ilustración, en diálogo con Zsu Szkurka- y Carta sobre los ciegos para uso de los que pueden ver (2017). Con estas obras afianzó un proyecto personal y coherente que pronto le valió la obtención del prestigioso premio Xavier Villaurrutia ${ }^{4}$ ya en el año 2001

1 Ha publicado, sobre todo, en editoriales independientes. Solo como muestra, sus libros han aparecido, en francés, en Christophe Lucquin Éditeur, Stock y Éditions Passage du Nord Ouest; en alemán, en Frankfurter Verlagsanstalt y en Documenta; en italiano, en Bookever y La Nuova Frontiera; y, finalmente, en inglés, en City Lights, Ravenna Press, 7 Vientos Press y Phoneme Media.

2 Sin imaginar el conflicto que se desataría con la editorial, después de su adquisición por el Grupo Planeta, por el vigésimo aniversario de su publicación, del que incluso The New Yorker se hizo eco (Mochkofsky, 2015). De forma muy resumida, la voluntad del autor de reformular el texto original con motivo de esta celebración -a la manera de la revisión de Jacobo el mutante en Jacobo reloaded, por ejemplo- no fue respetada por los editores. Por este motivo, Bellatin instó en Facebook a no adquirir ningún ejemplar y solicitó que se "despublicara" o se retirara del mercado.

3 Resulta interesante su recorrido por distintas editoriales, que aquí apenas hay espacio para esbozar; hay que tener en cuenta que también ha publicado en otros lugares tanto en Perú (Sarita Cartonera) como en México (Síntoma, Almadía y Sexto Piso), así como en Argentina (Sudamericana, Entropía, Mansalva y Eterna Cadencia), en Chile (Cuneta) o en Uruguay (Criatura Editora).

4 Un premio recibido con anterioridad por autores como Juan Rulfo, Octavio Paz, Juan José Arreola, 
por su obra Flores (2002). Un proyecto que tiene como nexo común, por un lado, la exploración de los límites del lenguaje y de la representación y, por otro, un cierto distanciamiento, dado, en parte, por el aparente desplazamiento espacial en que tienen lugar buena parte de sus narraciones. Destacan, así, respecto a este último punto, sus textos situados en el Lejano Oriente, como El jardín de la señora Murakami. Oto-no Murakami monogatari (2000), La escuela del dolor humano de Sechuán (2001) o Shiki Nagaoka: una nariz de ficción (2001) -el texto que aquí se abordará- y, con posterioridad, el relato "Bola negra” -en Pájaro transparente (59-74)-, El pasante de notario Murasaki Shikibu (2011), o también en el Oriente Próximo, y su fascinación por el sufismo, de lo que no me voy a ocupar en estas páginas.

Se observa, asimismo, otro tipo de distanciamiento, subrayado por el protagonismo de personajes marginales, periféricos, víctimas de una morbosa y sutil estética de la crueldad (enfermos terminales, mutilados, deformes, tetrapléjicos) y, sobre todo, por la hibridez genérica de sus propuestas teóricas implícitas, entre el ensayo crítico, la traducción y el relato. Esta hibridez, habitualmente desarrollada en textos de difícil clasificación, cada vez más fragmentarios (Cfr. Pitois-Pallares, 2011), breves, aborda el cruce de fronteras discursivas intermediáticas, como las de la narrativa escrita y la imagen visual, sobre todo a través de la fotografía ${ }^{5}$ : por ejemplo, ya en la edición de Damas chinas (1998), con imágenes de Víctor Garrido; o sus colaboraciones con Ximena Berecochea, desde la portada de El jardín de la señora Murakami (2000), en las imágenes que acompañaban Flores (2001, 2004) y Jacobo el mutante (2002), además del caso que aquí se detallará; en diálogo con fotografías de Graciela Iturbide, la autora de Juchitán de las mujeres, 1979-1989 (2010), en el proyecto conjunto Demerol without Expiration Date-El baño de Frida Kahlo (2008); o con sus propias imágenes, cada vez más descentradas, fuera de foco, difuminadas y fantasmáticas, en Perros héroes (2003), Los fantasmas del masajista (2009) o Biografía ilustrada de Mishima (2009). Una hibridez

\footnotetext{
Salvador Elizondo, José Emilio Pacheco, Carlos Fuentes, Sergio Pitol o Carlos Monsiváis, entre muchos otros, y otorgado por los propios pares, por los demás escritores -no lo olvidemos-, a través del Consejo Nacional para la Cultura y las Artes (CONACULTA), y que en esta convocatoria contaba con un jurado formado por Alí Chumacero, Margo Glantz -uno de sus mayores apoyos-, Juan Villoro y Bárbara Jacobs. 5 Aunque, últimamente, también a partir de la ilustración, en su colaboración con zsu szkurska, en proyectos como Jacobo Reloaded (2014) o Retrato de Mussolini con familia (2015), o las portadas narrativas de sus últimas ediciones en inglés en Phoneme Media, en traducción de Jacob Steinberg en el caso de Jacob the Mutant (2015), y de David Shook, en The Large Glass (2016), The Uruguayan Book of the Dead (2017), y también la reedición de Shiki Nagaoka: A Nose for Fiction (2017).
} 
que Bellatin ha bautizado como "fotografía narrativa", con la que subvierte las instancias de la realidad y la ficción, a partir de la narración con imágenes que se resisten a la función de mero apoyo para ilustrar el texto y que se erigen como discurso propio y, a menudo, discordante, contradiciendo a la palabra que acompaña ${ }^{6}$. Esta fascinación por la imagen le ha llevado, como es sabido, incluso, a realizar presentaciones con proyección de diapositivas, o de videoinstalaciones, dando lugar a la performance o escenificación, y a adaptar -o colaborar en la adaptación de- textos propios en otros formatos, coreografiados, por ejemplo, o musicados y filmados ${ }^{7}$, explorando con ello el desarrollo de una misma historia en distintos lenguajes narrativos.

Shiki Nagaoka: una nariz de ficción, publicada por Sudamericana en Buenos Aires el año 2001, se presenta como una biografía del escritor japonés del mismo nombre, que Bellatin había inventado en una entrevista (Cfr. Mochkofsky, 2015), aunque desde la segunda parte del título se apunte ya, no obstante, a su verdadera naturaleza narrativa, ficcional. A partir del título no resulta extraño que parte de la historia se centre en algo tan anecdótico como la desmedida magnitud del órgano olfativo del protagonista: una diferencia, también simbólica, que lo distingue y lo enfrenta a una sociedad caracterizada aquí, tradicional y tópicamente, por su uniformidad, y a unos individuos dotados de un apéndice nasal discreto y casi ausente, como característica fenotípica. La nariz cobra protagonismo ya en el peritexto inicial, la portada, donde aparece una fotografía que el lector identifica de inmediato con la posible imagen del biografiado, puesto que es costumbre extendida exhibir el retrato del sujeto en cuestión en la cubierta de un libro donde se traza su biografía (cfr. Doumet 13-23), algo que se asume casi como una convención literaria. Esta foto, envejecida y trunca, manipulada, pone en evidencia, por

\footnotetext{
6 Procedimiento presente también en otros artistas experimentales que juegan con el discurso escrito y la traducción, como es el caso de Young-Hae Chang Heavy Industries, en Corea del Sur, por ejemplo, en obras como Travelling to Utopia (Cfr. Walkowitz 203-234).

7 Brevemente, y sin ánimo de exhaustividad, cabe recordar algunos de estos procesos. Salón de belleza, por ejemplo, fue adaptado al teatro en 2002 por Alberto Chimal e Israel Cortés, en un espectáculo dirigido por este último y puesto en escena por la Compañía Raus (Compañía Mexicana de Circo de Cámara) en el Centro Nacional de las Artes (Cenart). Jacobo el mutante ha sido coreografiada por el grupo de danza Íntegro, dirigido por Óscar Naters e interpretado por Ximena Ameri y Alonso Núñez el 10 de mayo de 2013 en el Teatro de la Alianza Francesa de Lima. Otras obras del autor han sido también escenificadas, de algún modo, como es el caso de la presentación de Perros héroes (2003) en el claustro de Sor Juana, en México, en la que se aludía a una supuesta puesta en escena de la obra, en diversos lugares de la ciudad, que nunca se había producido, o la adaptación en 2012 del relato "Bola negra" en la película homónima, subtitulada "El musical de Ciudad Juárez", realizada por el propio Bellatin junto a Marcela Rodríguez, quien, asimismo, llevó a cabo la musicalización de fragmentos de ese mismo cuento.
} 
su ausencia, el apéndice nasal en cuestión, del mismo modo en que el propio título, otro peritexto, subraya su presencia, aunque la remite al reino de la ficción, como ya se ha apuntado ${ }^{8}$.

Otros dos peritextos, epígrafes esta vez, siguen apuntando en la misma dirección: el primero, procedente de un supuesto anónimo japonés medieval, del siglo XIII, titulado, por supuesto, La nariz, y el segundo, un fragmento de una obra también del mismo nombre, en japonés (Hana, 1916), firmado esta vez por Rynosuke [sic] Akutagawa (1892-1927) ${ }^{9}$, más conocido por su relato Rashomon (1917), adaptado al cine por Akira Kurosawa en 1950, y compañero de generación de Junichiro Tanizaki (1886-1965), autor del famoso Elogio de la sombra (1933), también mencionado, accidentalmente, en el relato, aunque resulte más importante en otra obra anterior de Bellatin, ya citada, El jardín de la señora Murakami. Oto no-Murakami monogatari. Ambos textos -el medieval y el de Akutagawa-, citados apenas en el umbral del mismo, aparecen reproducidos en su totalidad, dada su brevedad, al final del libro, también como peritextos (Shiki Nagaoka: una nariz de ficción 81-94), encerrando el relato sobre Shiki Nagaoka en una especie de marco que lo encaja dentro del espacio de la ficción y dentro de la tradición de la literatura japonesa, reforzando con esas dos figuras de autoridad la sensación de pertenencia a la misma. Como indica Mario Bellatin en una cita algo larga, pero que vale la pena mencionar:

En Shiki Nagaoka aparecen dos textos originales: el del siglo XIII y el de Akutagawa. Nadie sabe quién los escribió. Al final no estoy haciendo solamente un libro sino que me meto a hacer libros de tiempos y espacios que no me deberían de corresponder: yo no tengo nada que ver con Japón. El resultado es que me inserto en una tradición: ¿cómo no va a ser así si mi texto está avalado por un texto del siglo XIII japonés y por Akutagawa?, y al final de este juego de confusiones no creo que alguien pueda reconocer cuál es mi texto, cuál el de Akutagawa o cuál el del siglo XIII, aunque hay quien dirá: "Seguro el de

8 Algo más evidente, si cabe, en el subtítulo de su traducción al inglés, realizada por David Shook y publicada en Phoneme Books: “a Nose for Fiction", en cuya portada, además, se muestra lo que, en la primera edición en español, en Sudamericana, se eliminaba: la nariz. La ausencia se hace presencia.

9 Nombre que ha sufrido una ligera variación respecto al original en su transcripción en caracteres "roma-ji" (Ryunosuke) -aunque es cierto que, a veces, las vocales dobles japonesas se simplifican, como en este caso- para crear, acaso, confusión en el lector, jugando con su probable conocimiento previo de que "rino-" corresponde al prefijo de origen griego que significa "nariz", hecho que puede desorientar a algunos lectores y hacerlos dudar sobre la existencia de autor de tan oportuno nombre. 
Akutagawa es mejor". Está bien, puedes decir que uno es mejor que otro, pero no puedes decir cuál es de cuál, y si acaso alguien pudiera hacerlo qué importa: ¿cuál es la diferencia que tú leas el texto de Akutagawa pensando que lo hizo él o yo o fulano de tal? Eso me hace preguntarme, nuevamente, por el papel de los elementos constitutivos de la literatura: el tiempo y el espacio, pero también por quién escribe los libros. Siempre quise hacer libros enmascarados en los que nunca supieras quién es el autor y donde gracias a una objetividad aparente sacaras tus propias conclusiones, reconstruyeras tu propio texto. Esto me puso a pensar: yo ni siquiera soy un escritor sino un traductor de libros inexistentes. He traducido Shiki Nagaoka o El jardín de la señora Murakami. (Ctdo. en Calera-Grobet 18)

Efectivamente, en el fondo, lo que se está planteando es una revisión de la idea de autoría, y de su parafernalia ${ }^{10}, \mathrm{y}$, aunque no lo parezca, la importancia del papel del lector. En este sentido, el texto Shiki Nagaoka: una nariz de ficción se constituye como hipertexto de unos textos literarios previos o hipotextos inciertos: un hipotexto B, el relato de Rynosuke [sic] Akutagawa, que amplía o amplifica ${ }^{11}$, y que se basa, a su vez, en un hipotexto A, el anónimo medieval, que lo inserta dentro de la tradición. Sin embargo, en Shiki Nagaoka se niega, indirectamente, la inspiración del hipotexto B, de 1916, al considerarlo de procedencia directa de los datos biográficos de Shiki Nagaoka recopilados por el narrador. El título completo de ese hipotexto B, de Rynosuke [sic] Akutagawa, es ZenchiNaigu-no-Hana y, de hecho, ese es el verdadero nombre del biografiado, Naigu Zenchi, aunque un dato así, que implica la identidad del protago-

10 Resulta mítica ya, la acción “Dobles de escritores” que llevó a cabo Bellatin (“¿Le gusta este jardín que es suyo?" 60-61), cuando organizó en 2003 un coloquio con los autores Margo Glantz, Salvador Elizondo, Sergio Pitol y José Agustín, al que, en verdad, acudieron actores que los interpretaron, planteando la pregunta, una vez más, respecto a la importancia o a la necesidad de la presencia física de un escritor más allá de sus palabras. Acción que recuerda, de algún modo, a la del cineasta experimental alemán Alexander Kluge, y a su proyecto de reinterpretación de la historia, a partir de la grabación de actores encarnando a grandes figuras del pasado.

11 Este proceso de ampliación o amplificación, si se emplea el calco del término latino de amplificatio, utilizado para denominar una de las prácticas frecuentes en las traducciones medievales, es ya frecuente en la obra de Bellatin, aunque quizás el caso más evidente sea el de Jacobo reloaded (2014), versión extendida de Jacobo el mutante (2002), también a la manera musical, y que hace pensar en la fecunda idea del homo sampler. Por otro lado, la técnica del ensamblaje de textos -tanto ajenos como propiosque adquieren un nuevo sentido con su nueva publicación, reconfiguración y recontextualización ya era practicada por las vanguardias históricas, con las que Bellatin dialoga, como es sabido, a través del tiempo. 
nista, aparezca apenas mencionado al principio (16). Con ello se pone en duda la cadena de identidades, referencias y su jerarquía.

El personaje Shiki Nagaoka, o Nagaoka Shiki, como se ordena el nombre y el apellido en japonés, resulta diferente, excéntrico, no sólo por su enorme nariz -que nunca se verá-, que hierve diariamente como tratamiento de reducción de su tamaño, y que debe sostener de forma manual o mecánica para poder comer -con ayuda de un sirviente o con un aparato de su invención- sino por su vocación: religiosa, primero, y literaria, después... aunque se trate de una misma cosa para el personaje, a fin de cuentas. El relato se presenta como los apuntes o fragmentos de un biógrafo, ficcional -aunque su nombre coincida con el del autor, Mario Bellatin, desde la portada-, que se articula como un narrador no fiable, con expresiones como "Hay quienes dicen que..." (11), "se cree que..." (15), "algunos estudiosos de la literatura afirman que..." (21-22), dando pábulo a distintas versiones posibles de los hechos narrados. Aunque no nos detendremos aquí, en este concepto acuñado por Wayne C. Booth en The Rhetoric of Fiction (1961), vale la pena subrayar su práctica, que lo entronca con escritores canónicos tan distintos como Jorge Luis Borges, Juan Rulfo o Roberto Bolaño, que tienen en común el empleo abundante y estructural de ese tipo de narrador (cfr. Gras 2017).

De hecho, estos apuntes biográficos cuentan la historia de un escritor (ficticio o apócrifo), de una manera similar a los personajes históricoficcionales de las Vidas imaginarias (1896) de Marcel Schwob o de Jorge Luis Borges en Historia universal de la infamia (1935) o, quizás, aún más parecida a la estrategia empleada por Vladimir Nabokov en Pale Fire (1962), donde el crítico Kinbote analiza la obra del ficticio John Shade - “Sombra”, en inglés, significativamente-, o la de Augusto Monterroso y su Eduardo Torres en Lo demás es silencio (1978). Una estrategia paródica empleada también por autores como Roberto Bolaño en La literatura nazi en América (1996) o por César Aira en Varamo (2002), donde se narra, en esta última, la historia del repentino poeta de la patria en Panamá, por citar sólo dos posibles ejemplos. Se trata, pues, de una forma narrativa paródica e híbrida (cfr. Herrero-Olaizola, 2000) que pone a prueba una y otra vez al lector y desplaza constantemente la frontera entre realidad y ficción, apostando por la confusión y el espacio intersticial de ambigüedad. Una literatura que explora, precisamente, ese espacio de la impostura deliberada, también conocida en ámbitos artísticos por su nombre en inglés, el fake, recordando, en todo momento, su punto de partida, la 
ficción, como bien ha sabido destacar K. K. Ruthven en Faking Literature (2001), ya desde su título, irónicamente tautológico y provocador.

Por lo demás, la historia personal de Shiki Nagaoka resulta bastante intrascendente, por no decir banal, entre el monasterio y, precisamente, un taller de fotografía donde trabaja -con excepción de algunos episodios oscuros, como el repudio de sus padres, la expulsión del monasterio, la muerte del sirviente a quien intentó seducir sin éxito, o su propia muerte en manos de unos atracadores-. No obstante, su trayectoria literaria se caracteriza por su gran ambición. De su nariz, curiosamente, se dice poco de forma específica, el narrador menciona apenas que:

los primeros cuentos que escribió Nagaoka Shiki, respetuosos en extremo de la técnica sampopo que practicaron los monogatarisén -creadores de cuentos-, tratan de asuntos relacionados con una nariz. Nagaoka Shiki creó cerca de ochocientos monogatarutsis -relatos cortos-, entre los diez y los veinte años de edad. Desde algunos que siguen preceptos clásicos, dedicados sólo a describir las dimensiones del apéndice, hasta los que hacen referencia a extrañas distorsiones tanto en el sentido del olfato como en la capacidad para respirar. Al final de esa etapa, que culminó cuando el escritor ingresó a un monasterio, hizo una serie de monogatarutsis de carácter erótico que tenían también la nariz como protagonista. (12-13)

Como es obvio, aquí se hace eco, velada e irónicamente, de esa creencia popular que conecta las dimensiones del apéndice nasal masculino de un individuo con el tamaño de su órgano sexual. Asimismo, aparte de los monogatarutsis de juventud ya indicados, las obras de Shiki Nagaoka referidas en el relato biográfico son el ensayo escrito tras la posguerra, de revelador título, Foto y palabra (Life, 1953; Espasa-Calpe, 1960), el Tratado de la lengua vigilada (Fuguya Press, 1962) y el texto intraducible titulado con un 'kanji' indescifrable, así como un diario póstumo ${ }^{12}$ (Shiki Nagaoka: una nariz de ficción 43), textos que coinciden, sospechosamente, con la teoría narrativa del propio Bellatin sobre la traducción literaria y la foto-

12 Se mencionan también otros proyectos inconclusos como esa larga novela que se proponía como la versión masculina del Genji monogatari (1008), cercana a La búsqueda del tiempo perdido (1913) de Marcel Proust, y que acabará destruida por el fuego (Shiki Nagaoka: una nariz de ficción 18). Como se recordará, el Genji monogatari fue escrito por Murasaki Shikibu, nombre que Bellatin toma como punto de partida para El pasante de notario Murasaki Shikibu (2010b), el divertimento en homenaje a su amiga y mentora Margo Glantz. 
grafía narrativa. Según su biógrafo, Shiki Nagaoka se entusiasma por la fotografía porque "tenía que ver con su temprana pasión por lo literario. Consideraba un privilegio contar con imágenes visuales enteras, que de algún modo reproducían al instante lo que las palabras y los ideogramas tardaban tanto en representar" (15). De hecho, el intento de aunar fotografía y literatura en el proyecto de Shiki Nagaoka se encarna en el propio texto que leemos, ya que el relato biográfico va acompañado por imágenes fotográficas que son tratadas como huellas de una existencia, pruebas o testimonio para sostener, con la documentación gráfica o visual, la supuesta veracidad de lo narrado, aunque lleve a cabo un "uso de la foto como un elemento de manipulación de la realidad" (26).

Respecto a la traducción literaria, se cuenta en la biografía cómo Shiki Nagaoka solía escribir primero sus textos en francés o en inglés para traducirlos él mismo después al japonés, buscando con ello el distanciamiento del texto traducido y, con ello, lo que todavía queda y puede transmitirse como literario, la esencia más allá del lenguaje mismo. Así, en su Tratado de la lengua vigilada, señala que:

Solo haciendo circular los relatos de una caligrafía occidental a ideogramas tradicionales, es posible conocer las verdaderas posibilidades artísticas de cualquier obra. Extrañamente, pese a ese aparente apego a las lenguas foráneas, Nagaoka Shiki en ningún momento dejó translucir en su trabajo la mínima influencia de literaturas ajenas. (13)

Esta es, de hecho, la poética del propio Bellatin. Como el mismo autor ha manifestado en una entrevista:

Una buena traducción puede llenar más que un original. Por eso yo juego en muchos libros con la literatura japonesa. No es que me interese especialmente con la literatura japonesa, que sí me interesa pero como me interesan otras, sino que trato de mostrar que lo literario, lo que queda de pasar de un ideograma a una lengua occidental, queda intacto. Me parece fantástico que una buena traducción de un escritor japonés, que escribió en ideogramas, siga conteniendo literatura y se pueda ingresar en los universos que plantea ese escritor. (Plaza 112).

Lo literario sería, por tanto, lo inmanente, lo que permanece, lo que pasa la prueba de fuego de la traducción conservando el calor del texto original, lo que logra transmitirse a pesar del obstáculo del lenguaje - 
recordando y refutando la famosa frase de Robert Frost: "Poetry is what gets lost in translation"-, visto este no como un vehículo de comunicación, en ocasiones, sino como un impedimento que desea eliminarse, tal y como sigue formulando en la misma entrevista:

A mí la lengua en sí me molesta y me molesta que el lenguaje sea demasiado extenso. Por eso hago siempre un trabajo de sustracción hasta llegar a una suerte de neutralidad, donde el que hable sea el silencio, lo que no está dicho. Yo sería feliz si redujéramos el idioma al mínimo y eso está en contradicción con la idea que se tiene del escritor, como de un ser de imaginación desbordada y con manejo del lenguaje. Yo, en la primera etapa de mi trabajo, tengo una imaginación desbordada y, a medida que avanzo, la voy reduciendo y eliminando. Y, por supuesto, no creo que el idioma influya en el escritor. Yo preferiría que el español fuera un idioma más compacto [...] además yo trato de que la lengua casi no exista, que sea sólo un vehículo lo más llano y lo más transparente posible. (112)

Por otro lado, en cuanto a la "fotografía narrativa", ya mencionada al principio de estas páginas, interesa recordar, más allá de un paréntesis, que Mario Bellatin se formó en la facultad de Ciencias de la Comunicación en la Universidad de Lima y resultó becado en 1987 para estudiar guion cinematográfico en la Escuela Internacional de Cine Latinoamericano de San Antonio de los Baños, en Cuba, patrocinada por Gabriel García Márquez. Este dato ayuda a comprender la importancia que otorga a la imagen como parte integrante del discurso narrativo y también por su ritmo interno, por su tempo, ya que, como él mismo ha observado, "curiosamente, leer un libro mío demora el tiempo de ver una película" (Escribano s/p). Además, esta misma preocupación por la hibridez de la palabra y la imagen, por una voluntad semiótica más amplia, ha guiado también su actividad docente como director de la Escuela Dinámica de Escritores, en México D. F., con el objetivo de enseñar las reglas del juego del escritor y estructurar su discurso a través de la historia de otras literaturas y el contacto con otras artes (fotografía, teatro, pintura, arquitectura...), todo combinado con talleres monográficos impartidos por escritores y especialistas reconocidos ${ }^{13}$. En este sentido, Bellatin ha sido

13 Así, por ejemplo, Jaime Moreno Villarreal se encargaba de "Escritura y visualidad"; Gabriel Figueroa impartió el curso de "El discurso fotográfico", donde se proponía el trabajo con "fotografías dadas", es 
consciente de forma temprana de lo que se ha dado en llamar el "giro icónico" o "visual" dentro del ámbito literario, ese cambio paradigmático que juega con la conocida referencia al "giro lingüístico" del arte (Cfr. Rodríguez Freire, 2016).

La importancia de la imagen en el proyecto narrativo de Bellatin se revela ya en las fotos del autor en las solapas y las contraportadas de sus libros. Se trata de fotografías orquestadas, escenificadas, en las que su exhibicionismo cuestionador e interpelador juega, de forma provocadora, con el lector. En estas imágenes del autor se construye un personaje, una máscara, de filia fetichista y sugerente sadomasoquismo, a partir de la ostentación de la diferencia, de la ortopedia, de su brazo artificial y de los arneses que lo sujetan y lo convierten en una especie de cyborg literario, flanqueado por perros embalsamados. Esas imágenes, firmadas por distintos fotógrafos -como Raúl González, Janet Jarman o Daniel Mordzinski, por citar a unos pocos- constituyen una muy peculiar corpografía autorial evidente (cfr. Pérez-Fontdevila y Torras, 2016 y Pérez-Fontdevila, 2017), destacada ya por algunos críticos (cfr. Camenen 1-2; Guerrero 243-270), en la que debería profundizarse, puesto que parece sugerir la correspondencia entre la representación del cuerpo del autor con el cuerpo de sus textos, fragmentarios y reasignados, a menudo: textos intercambiables como sus prótesis, y que tienden a la espectacularización.

Por otra parte, si el sentido de la vista suele ser el primero al que se recurre para comprobar la realidad inmediata, también es el más susceptible a engaño, como ya consideraron los escritores del Barroco, conscientes del simulacro de la imagen, como evidencia el famoso soneto de Sor Juana Inés de la Cruz "Este que ves, engaño colorido", donde cuestiona la representación mimética de un retrato. Si el lector parte del principio de "ver para creer", como Santo Tomás, puede tratarse de un punto de partida muy débil, como se pone aquí en evidencia, a través de la narración ${ }^{14}$.

decir, con "fotos viejas, colección de postales, fotos familiares o fotos tomadas de un viaje" (El arte de enseñar a escribir 131); Milagros de la Torre proponía como ejercicio elaborar un "relato visual" (129) en "Reestructurando la fotografía"; César Guerra también se ocupaba de esta cuestión en "Relato y fotografía”; por su parte, Ximena Berecochea participó con el curso "Signo lingüístico y signo visual” y con "Fotografía, simulación y narrativa”, esta última junto a Gerardo Montiel Klint -quien se ocupó asimismo de "Intertextualidad en la nueva narrativa visual" -, en cuyo programa aparece, precisamente, el ensayo de Joan Fontcuberta El beso de Judas. Fotografía y verdad (2015) como bibliografía de referencia (169). 14 No en vano, uno de los dos epígrafes que sirve de pórtico a Carta sobre los ciegos para uso de los que puedan ver (2017) es una cita de Diderot que reza: "Recuerdo que alguna vez me he ocupado de esta especie de anatomía metafísica y encontré que, de todos los sentidos, la vista es el más superficial (...)” (7). Se trata de una nueva entrega de Bellatin donde vuelve a cuestionarse, una vez más, el supuesto principio de autoría. 
El relato va acompañado por imágenes fotográficas que son tratadas como pruebas iconográficas para sostener, con la documentación visual, la veracidad de lo narrado. No obstante, coherencia y verosimilitud no implican necesariamente relevancia ni verdad, en lo que se revela como una pura construcción lingüística sin referente extratextual, un juego de ficción que pone de relieve la naturaleza espuria de la literatura. El juego del efecto de realidad con el lector, de hecho, es una constante en la narrativa de Bellatin que remite, inevitablemente, a los maestros, desde Marcel Schwob a Augusto Monterroso, pasando, desde luego por Borges, aunque aquí la referencia al Jusep Torres Campalans (1958) de Max Aub se haga necesaria, por su particularidad. En el caso de Aub, el efecto de realidad se sustenta con la aportación de las reproducciones de las obras del supuesto pintor, en una cuidada edición en color... obras realizadas por el mismo autor. En el caso de Bellatin, ese efecto de realidad se apoya en las fotografías en blanco y negro que se adjuntan como documento gráfico de ese pasado que se quiere hacer presente.

Hay que recordar que en El beso de Judas. Fotografía y verdad (2015), del fotógrafo y teórico Joan Fontcuberta, se encuentra ya, de forma explícita, en el título la principal cuestión en torno a la que gira tanto el proyecto artístico como la inquietud teórica de este especialista, que se centra en "[...] la ambigüedad intersticial entre la realidad y la ficción" (13), y que, de hecho, como él mismo ironiza, tiene que ver más quizás con la ontología que con la estética. Un interés compartido con Bellatin, por otro lado. También en el título se encuentra resumida, de algún modo, de forma metafórica, su perspectiva: la fotografía es tan traidora como el beso de Judas: “Toda fotografía es una ficción que se presenta como verdadera. [...] la fotografía miente siempre, miente por instinto, miente porque su naturaleza no le permite hacer otra cosa", (17). Por lo tanto, desde ese ángulo: "Fotografiar, en suma, constituye una forma de reinventar lo real" (35). Algo que parece contradecir la idea generalizada de la fotografía como evidencia o soporte de una realidad objetiva.

Llegados a este punto, quizás valga la pena considerar, con el mismo teórico, en Indiferencias fotográficas y ética de la imagen periodística (2011), que "la imagen fotográfica transmite un exceso de verdad [...] se asocia a un puro reflejo de lo real. La fotografía no solo contiene realidad sino que la rebosa" (7). Incluso llega a hablar de una "sobredosis de verdad" (9), como si la verdad fuera, de hecho, una droga, y pudiera resultar igual de adictiva, tentadora y peligrosa. Acaso, quizás, aventura, por la 
supuesta ratificación que implica, y que identifica con el "noema de la fotografía que Barthes evocaba con tanta insistencia: 'esto ha sido' [...]” (8).

Advierte que esa identificación entre imagen y verdad parte del mismo origen de la fotografía, del daguerrotipo. Ya Roland Barthes en su ensayo clásico, La cámara lúcida. Sobre la fotografía (1980), había subrayado esa estrecha relación, como si se tratara de "una especie de cordón umbilical [que] une el cuerpo de la cosa fotografiada a mi mirada: la luz, aunque impalpable, es aquí un medio carnal, una piel que comparto con aquel o aquella que han sido fotografiados" (128), de tal modo que, reflexiona, la "fotografía es literalmente una emanación del referente. De un cuerpo real, que se encontraba allí, han salido unas radiaciones que vienen a impresionarme a mí, que me encuentro aquí" (Barthes 126). Sin embargo, Fontcuberta (2011) recuerda, muy pertinente y apropiadamente, cómo ya a principios del siglo XX, en un artículo pionero de Edward Steichen, titulado, de modo enfático, "Ye, Fakers" [Ustedes, impostores] (1903), este apuntaba: "Una fotografía no puede verse descrita simplemente en términos de 'falsa' o 'verdadera', de manipulada o no manipulada. [...] Cada fotografía no es más que una falsificación [fake] de principio a fin; una fotografía impersonal y no manipulada es prácticamente imposible"' (24-25). Por lo tanto, como ya adelantaba el mismo Fontcuberta: "toda fotografía es necesariamente una construcción [...] en la medida en que no coincide con la realidad misma, y aun a pesar de que mantenga estrechas conexiones con ella" (22). Lo que aporta, sin duda, es un efecto de realidad innegable, un simulacro de esa realidad a la que se remite de forma especular y, por tanto, deformada. Y ese efecto de realidad, esa supuesta objetividad, continúa señalando, "es tan solo una cuestión de estilo" (29), se trata de una 'sintaxis', del respeto a unas normas o convenciones internas, entre las que destaca, por ejemplo, el empleo del pie de foto, es decir, de la parte del texto que guía al lector-espectador en su interpretación de la imagen. Exactamente, tal y como ocurre en Shiki Nagaoka: una nariz de ficción. Entre las funciones del pie de foto cabe destacar, así, la orientación en la recepción de lo que se muestra, su posible aclaración -o distorsión, no hay que olvidarlo- y la explicación de su contexto; o, en palabras de Fontcuberta (2011):

El pie de foto, por tanto, es la información verbal necesaria que simultáneamente construye el valor de la información visual y la conecta con el texto principal, con otras leyendas y con otras imágenes. La función verdadera de la leyenda es hacer 
que el lector vuelva a mirar la imagen, vea más hechos (datos) en ella y los conecte con otros hechos; así el relato queda contextualizado. (33)

Para reforzar ese efecto de realidad buscado, Bellatin adjunta, efectivamente, a su biografía apócrifa o bioficción un álbum fotográfico (Shiki Nagaoka: una nariz de ficción 47-80), perteneciente, en apariencia, al escritor japonés, Shiki Nagaoka, como soporte documental. Dentro de este archivo fotográfico privado, o "recuperación iconográfica”, como aparece en el libro ${ }^{15}$, descripción certera del procedimiento llevado a cabo por Ximena Berecochea, una de las colaboradoras del escritor en otros textos, como ya se ha indicado, se pueden distinguir distintos tipos de imágenes, que se remiten a:

a) Los orígenes: retratos de familiares o personas relacionadas con el escritor japonés. Entre estos, cabe destacar las imágenes de los padres, la hermana y la sobrina-nieta de Nagaoka (49, 52 y 72); se observa, asimismo, una fotografía del supuesto escritor, la misma de la portada del libro y que, al parecer, según reza el pie de página, ha sido "manipulada por su hermana, Etsuko, con el fin de evitar que el autor fuera considerado un personaje de ficción" (29); por otro lado, se muestran dos figuras de lejos, que apenas pueden intuirse y corresponderían al propio supuesto escritor japonés, esta vez acompañado del sirviente de quien se enamoró y que le delató a las autoridades (54); finalmente, se exponen retratos de grupos correspondientes a compañeros de curso -hay que destacar el círculo en el que se enmarca a Shiki Nagaoka: no puede distinguirse a nadie-, fieles del monasterio en que se recluye el escritor, fotografías de clientes de su kiosco de revelado y el reparto de la película Tarde de otoño, del director Ozu Kenzo (50 arriba, 61, 64 y 67 abajo);

b) Los espacios recorridos o frecuentados por el autor: el monasterio budista en el que se encierra (Shiki Nagaoka: una nariz de ficción 51), un bosque aledaño (57, abajo), el canal que cruza el monasterio (63), imágenes que, efectivamente,

15 Además, Bellatin (2001) especifica: "Procedencia de las ilustraciones: Archivos fotográficos de las familias Nagaoka y Kasuga” (6). A continuación, como en algunas ocasiones hay varias fotografías en cada página, se indicará, en cada caso, la posición en la que se encuentra la imagen concreta, bien sea en la parte de arriba o en la de abajo. 
podrían ser cualquier lugar. U otras, como la de la península de Ikeno (74), que sirven más bien de paisajes para contextualizar la vida cotidiana del escritor, posibilidad hacia la que apunta, sobre todo, el mapa del radio de acción de Nagaoka (71), mientras que, finalmente, hay algunas que resultan algo diferentes, puesto que parecen servir para corroborar la existencia no sólo del personaje del escritor, sino de su importancia posterior, de su fama póstuma, dado el interés que ha despertado entre sus seguidores, los nagaokistas. Así, por ejemplo, a partir de las indicaciones de los pies de foto: el edificio donde éstos se reúnen en el Barrio Latino de París (77) -nuevamente podría tratarse de cualquier lugar de casi cualquier ciudad-; o el despacho que se muestra del narrador mexicano que investiga su libro indescifrable (79), y que en la bibliografía aportada tras el relato biográfico se descubre como Pablo Soler Frost ${ }^{16}$; o un parque donde se halla enterrado el escritor japonés y que ha recibido, por ello, el nombre de Barrio de la Nariz (80), con lo que se confirma su trascendencia tras su muerte, su inmortalidad literaria, hasta el punto de ser homenajeado por sus conciudadanos, tras su repudio, y transformar la realidad, aunque sea en ese pequeño rincón del parque;

c) Los objetos pertenecientes al escritor o relacionados con éste: como algunas obras de arte ( 55,56 y 78), los instrumentos (casi de tortura) para tratarse la nariz (58, abajo; 59, 60 y 61, arriba; 75 y 76) y elementos tan cotidianos como su vajilla y calzado (68) o las ropas que utilizaba para hacerse pasar por su hermano gemelo y no ser reconocido por periodistas y críticos literarios (69), como si la apariencia de un gemelo pudiera ser muy distinta;

d) y, finalmente, de entre todos estos objetos, los más importantes, los escritos de o sobre Shiki Nagaoka: entre los últimos destaca una reseña sobre el Tratado de la lengua vigi-

16 Alusión al también escritor mexicano de culto Pablo Soler Frost (México, 1965), que, en el momento de la publicación de Shiki Nagaoka, había publicado De batallas (1984), aforismos sobre la guerra, y las novelas Legión (1991), La mano derecha (1999) y Malebolge (2001), las dos últimas sobre el destino de la familia Jensen, a la manera de una saga. Este narrador mexicano, además de ser también profesor de la Escuela Dinámica de Escritores, comparte con Bellatin no solo amistad y complicidad sino la voluntad experimental y la situación de sus relatos en lugares lejanos a México, normalmente en Centroeuropa. 
lada en el diario nacional Tomonomashimpo (53), algunos documentos como el del repudio familiar en el diario local y el de la expulsión del monasterio o la biografía escrita por su hermana Nagaoka Shiki: el escritor pegado a una nariz (57, arriba; 64, arriba; 62) y, entre los primeros, fragmentos de sus manuscritos rescatados de la hoguera, algunos "monogarutsis" de juventud, su libro Foto y palabra -donde aboga por una escritura narrativa en la que tenga cabida, precisamente, la imagen-, su diario póstumo, sostenido por su sobrinanieta, el símbolo o "kanji” de su libro intraducible, e incluso unos textos de arrepentimiento de los artistas del círculo del Mundo Flotante que no habían reconocido a tiempo su magisterio (58, arriba; 50, abajo; 66, 72, 73 y 67).

Por tanto, las fotografías cumplen, en teoría, con las convenciones propias de su función ilustrativa, como apoyo al relato biográfico, y siguen, en lo esencial, la gramática y la sintaxis de este género, requerido por ese lenguaje referencial, de mostrar la realidad a la que se remite, situando al autor en su contexto, en el espacio y el tiempo, y mostrando su producción. Especialistas en el análisis de la representación de la figura del escritor han hecho hincapié en la existencia de un sistema de figuración iconográfica que funciona de una forma relativamente estable (cfr. Durand, 2014), y que convierte, a menudo, a la persona en personaje, aunque, como indica David Martens (2012), esta forma de mostrar ese retrato del escritor puede subrayar, paradójicamente, su ausencia esencial: “tout ce qui, figuré, est placé sous le signe de l'écrivain participe d'une façon ou d'une autre de son iconographie (lieux de vie, relations personelles, objets intimes...), ce qui implique, bien evidemment, des images dont l'écrivain en tant que tel est absent." (162).

En este sentido, es sobradamente conocida esa cita de Roland Barthes en su ensayo ya mencionado, donde desarrolla el neologismo tan fecundo de "biografema" -acuñado en Sade, Fourier, Loyola (1971)-, que define del siguiente modo: "ciertos rasgos biográficos en la vida de un escritor me encantan igual que ciertas fotografías: a estos rasgos los he llamado "biografemas"; la Fotografía es a la Historia lo que el biografema es a la biografía” (62). Es decir, esa síntesis fragmentaria, o serie de instantáneas, que actúa en la tensión entre la aparición y la desaparición, en esa intermitencia, y al que el espectador o el lector debe darle un sentido. 
Las fotografías articulan un discurso coherente, reforzado, sobre todo, como se adelantaba, por el papel de los pies de foto, por sus indicaciones, por su papel prescriptivo. En este sentido, podría decirse que se pone en evidencia la fuerza de la coherencia sobre la relevancia, desde la perspectiva de la pragmática lingüística. De todas estas imágenes, no obstante, son acaso las últimas, las que tienen que ver con las huellas del cuerpo textual, las que pueden revelar las reglas del juego ficcional. Por un lado, el mismo empleo de palabras japonesas específicas, como 'monogarutsis', 'kanji' o el título del periódico Tomonomashimpo, refuerzan la sensación de texto traducido, produciendo un efecto exotizante y, con ello, el efecto de realidad del mismo, ya que dan fe del conocimiento del narrador del vocabulario japonés adecuado en las anotaciones a pie de página. Por otro lado, respecto a las imágenes en sí, al comprobar su contenido real, comienzan las esperadas sorpresas desde el principio. Por ejemplo, la imagen de los 'monogarutsis' (Shiki Nagaoka: una nariz de ficción; 50, abajo), en realidad, corresponde a una antología poética, Genei-bon kinto-bon kokin wakashu no kenkyu, más conocida como Kokin Wakashu o Kokinshu, realizada en el año 1120, para recopilar la poesía del período Heian (794-1185). El comentario en el periódico Tomonomashimpo del Tratado de la lengua vigilada (53) es, en cambio, un artículo de fondo sobre la revolución tecnológica de la información en Japón. La carta de repudio familiar aparecida en el diario local (57) se trata de un artículo de economía sobre tres mil empleados que participan en la introducción de un sistema de administración del conocimiento. En cuanto a los fragmentos manuscritos rescatados de la hoguera (58, arriba), no son más que una carta comercial por la transacción de un terreno que vale 1085 yenes. A su vez, las páginas de la biografía escrita por la hermana del autor, Nagaoka Shiki: el escritor pegado a una nariz, de evidentes ecos ronsardianos y quevedescos, que se muestran (62), unas proceden, seguramente, de un libro de historia japonesa, porque tratan del período Edo (ss. XVI-XVII), durante el que hubo un mayor control del contacto con los extranjeros, hasta el punto de prohibir el desembarco de naves y proceder a la expulsión de comerciantes portugueses. En cuanto al documento de expulsión del monasterio (64), se reproduce el informe de gestión de una fábrica y se apuntan ideas convenientes para los empresarios, tales como la reducción del salario de los trabajadores y de la superficie de la fábrica. Asimismo, los aparentes textos de arrepentimiento de los artistas del Mundo Flotante (67, arriba) son, en verdad, dos libros: una guía turística del Japón, a la derecha, 
y una reproducción de Ukiyo-e, a la izquierda, más dos papeles arrugados con los mismos poemas de la antología Heian, transcritos como ejercicios de caligrafía, que, en otra imagen anterior (50, abajo), se atribuían a imágenes de sus monogarutsis de juventud. Por otra parte, el mapa adjuntado corresponde a Kyu-shu, al sur de Japón, en la provincia de Fukuoka (71). Y, para finalizar, el libro que sostiene la supuesta nieta de Etsuko (72) no es el Diario póstumo de su tío abuelo, sino un libro de historia sobre el Japón del s. XIV, concretamente sobre el período Nambokucho (1336-1392), cuando tuvo lugar una gran batalla entre el emperador Go-daigo (dinastía del sur) y el de Komyo (dinastía del norte) ${ }^{17}$.

De hecho, tras el análisis de estas imágenes, puede deducirse que, para que se pueda establecer el pacto ficcional entre el lector y el escritor a través del texto, se deben aceptar las reglas indicadas -explícita o implícitamente- hasta un cierto punto: no sirve negarse por completo, desde una postura escéptica, a aceptar el juego, lógicamente. Esto, de hecho, plantea un problema de circulación del texto, puesto que imposibilita, prácticamente, su traducción al japonés, ya que, al comprender el auténtico contenido de los textos fotografiados, lo que producen en el lector es estupefacción y rechazo. Sin embargo, tampoco sirve la lectura obediente que acepta al cien por cien la supuesta verdad sostenida por las imágenes. En el caso de este texto se observa claramente el equilibrio necesario para mantener la magia narrativa, la suspensión de incredulidad en el lector (de la que ya hablaba Coleridge a principios del siglo XIX), ya que el hecho de conocer que el escritor es mexicano y ver que la historia se sitúa en Japón puede levantar sospechas a los lectores más avezados, con lo que no se lograría establecer el pacto de ficción, pero también se rompería ese pacto en los lectores que Umberto Eco (1996) llama "paranoicos" (119), los que creen a pie juntillas en la verdad (y no en la veracidad o la verosimilitud) de lo narrado, los que siguen cada información punto por punto e incluso la comprueban hasta sus últimas consecuencias $^{18}$. Porque el lector que siga paso por paso cada uno de los datos aportados en el relato de Bellatin observará que, mientras apa-

17 Esta información, como señalé al principio, fue aportada por mis informantes, las filólogas japonesas Kobayashi Keiko y Okamoto Kayoko, en un primer momento, a las que se sumó, posteriormente, Fukuda Yumeko. Véase también Dávila, 2012.

18 En este sentido, en su libro Seis paseos por los bosques narrativos (Lumen, Barcelona, 1996), Eco cuenta la anécdota referente a El péndulo de Foucault y al lector que le escribió una carta preguntando por qué no se había dado cuenta del incendio acaecido en el mismo lugar, el mismo día y a la misma hora en que aparece relatado -por otro lado, con gran detalle- en un fragmento de la obra. 
recen citados una y otra vez autores reales y conocidos por todos o por algunos (en el primer caso, el escritor mexicano Juan Rulfo y el peruano José María Arguedas -ambos atraídos por las posibilidades narrativas de la fotografía en su propia trayectoria literaria- y, en el segundo, Junichiro Tanizaki y Rynosuke [sic] Akutagawa o Pablo Soler Frost y el especialista en cultura japonesa Donald Keene), hecho que induce a la credibilidad de lo narrado como anclaje en la realidad, el archivo fotográfico documental adjunto es completamente ficticio, aprovechando la dificultad para comprobar tanto las distintas grafías japonesas como el desconocimiento de los sujetos retratados ${ }^{19}$, tal y como era de esperar y que revelaba el propio Bellatin en otra entrevista, sin ambages:

Hay muchas fotos que son reales y otras están tomadas de otras fotos. Todo se hizo de manera muy sencilla, en una mañana ya estaba listo. Hay una mujer que aparece en aquellas fotografías, ¿recuerdas? Bueno, pues ella es una amiga suya. Berecoechea le explicó la idea y ella le propuso ir a casa de su abuela. La abuela sacó todo el baúl. Entonces hay fotos que son tomadas por Ximena, luego fotos de los archivos de la abuela de su amiga y también fotografías de objetos inventados por Ximena. Lo más increíble de esto es que todo tiene el mismo tratamiento, todo se presenta con la misma pátina. (Calera-Grobet 20)

Por este motivo, en este caso, es necesario que se establezca un equilibrio entre el escepticismo y la credulidad, a un cincuenta por ciento ${ }^{20}$, para poder entrar en el mundo de ficción o universo narrativo del autor, dejándose llevar por la coherencia y verosimilitud del relato, sin comprobar cada uno de los datos, sin pensar en la relevancia de los mismos, a pesar de la sospecha razonable de la existencia de un posible juego narrativo. Sólo cabe disfrutarlo, como sigue apuntando Bellatin en la misma entrevista:

[...] Así se estructura el juego verdad-mentira-verdad-mentira, y a medida que se avanza en el libro estas mancuernas -todas inventadas, obviamente- resultan cada vez más absurdas. Esto,

19 De alguna manera, parodia, por supuesto, el prurito de críticos y biógrafos, que recogen hasta el último, digámoslo, "fetiche" de un autor en un obsesivo afán coleccionista que, a menudo, se pone en evidencia a sí mismo.

20 Apunta Fontcuberta (2015): "no debemos aceptarlo todo pero tampoco podemos rechazarlo todo. La duda es simplemente una herramienta de la inteligencia” (120). A través de este juego, Bellatin pone en evidencia las rutinas de las convenciones literarias de la biografía en que puede caer el lector, proponiendo una contravisión que las desautomatice y desarticule. 
por supuesto, no importa: es literatura. He ahí la importancia de la verosimilitud: que sea verdad o no lo sea no es asunto de lo literario. La función extraliteraria de la literatura -me refiero a su función antropológica o social- está puesta en tela de juicio. (21)

Este juego revela el ejercicio consciente de lo que se ha dado en llamar la postfotografía, cuyo origen y desarrollo analiza, de nuevo, Joan Fontcuberta en La furia de las imágenes. Notas sobre la postfotografía (2016), donde remite la idea de la "postfotograficidad" a los años noventa del pasado siglo, a partir del estudio de David Tomas, "From the Photograph to Postphotographic Practice: Toward a Postoptical Ecology of the Eye" (1988), en el que comienza a señalarse el progresivo descrédito de la "verdad visual", de la actividad fotográfica como representativa de la realidad, desde un extremo a otro, desde los recuerdos personales hasta el fotoperiodismo (La furia de las imágenes 30).

Fontcuberta despliega un "decálogo postfotográfico", casi a modo de manifiesto, en el que subraya, en primer lugar, algo fundamental: que el artista ya no tiene que producir una obra, sino "prescribir sentidos" (39), es decir, hacer que algo -lo que sea- sea recibido estéticamente. Aquí se observa, como es lógico, la huella de Marcel Duchamp, uno de los referentes fundamentales también del universo artístico de Bellatin ${ }^{21}$-inspiración para El gran vidrio (2007)- y, más concretamente, en este caso, la idea del ready-made y del objet trouvée $e^{22}$-en este caso, photo-trouvé-, como se mostrará a continuación. Y, con ello, en segundo lugar, como consecuencia obvia, que el artista sufre una importante transformación autoral, al mostrarse también como coleccionista, docente, historiador o teórico, entre otras máscaras posibles. Asimismo, hace hincapié también en su labor de reciclaje, de reutilización de materiales ya preexistentes, vaciándolos de contenido para posibilitar su circulación, de tal modo que "se normalizan las prácticas apropiacionistas" (39), entre las que se contarían opciones como "copia, cita, plagio, re-enactment, reciclaje, simulación, pastiche, parodia, alegoría, simulacro y revival” (56), aunque prefiera considerarlas “prácticas de adopción", puesto que, en el fondo, no

21 A quien Bellatin, claramente, homenajea en El gran vidrio (2007), que toma el título de la obra homónima, también conocida como “The Bride Shipped Bare by Her Bachelors, Even” (1915-1923), creada por ese alter ego duchampiano trans, Rrose Sélavy.

22 Objetos como los que el propio Bellatin escoge cuidadosamente y recoge de las ruinas urbanas de los fraccionamientos abandonados de Ciudad Juárez para alinearlos, sacarlos de contexto y dotarlos de un nuevo significado, en el musical Bola negra (2012), que realizara junto a Marcela Rodríguez. 
se trata de un acto de desposesión, sino de reasignación, reorientación y tutelaje. En este sentido, "se reformulan modelos alternativos de autoría, coautoría, creación colaborativa [...]” (39). Así, por ejemplo, en este caso nos encontraríamos con una doble adopción: por un lado, la del álbum familiar de la amiga japonesa de Berecochea, que decide compartirlo con Bellatin, cruzando así la frontera de lo privado a lo público, descontextualizándolo del ámbito propio -sobre el que tanto y tan acertadamente ha escrito, por ejemplo, Marianne Hirsch en Family Frames. Photography Narrative and Postmemory (2012)-, para recontextualizarlo y reconvertirlo. Aquí interviene la fotógrafa Ximena Berecochea, quien en "Diferentes cuerpos estructurales", un texto sobre su experiencia como docente en la Escuela Dinámica de Escritores ya referida, apunta:

Si se parte de un estudio comparativo en torno a los rasgos sígnicos literarios y fotográficos, se abren las puertas al vasto terreno representacional de estos dos campos en el que se nos presentan temas tales como la disputa entre texto e imagen por la primacía en el proceso imaginativo, tanto de creación como de recepción de una obra; la relación que guardan estas dos formas con lo que representan y por lo tanto cómo se les relaciona, o no, con la realidad; el juego de verdad y mentira asociado al hecho de mostrar y no mostrar; los trabajos ecfrásticos -es decir, aquellas representaciones visuales- que conforman un vasto repertorio que invita a una reflexión en torno a lo que buscan los escritores al recurrir a obras artísticas visuales e insertarlas verbalmente en sus obras. (El arte de enseñar a escribir 21)

Berecochea subraya aquí precisamente esa posible disputa "por la primacía en el proceso imaginativo" que, en el ámbito creativo, cuestiona o tensiona la instancia autorial: a pesar de aparecer, como es lógico, en los créditos, por la producción material de las fotografías, parece ceder también parte de su autoría a Bellatin, por el hecho de ser éste quien, en última instancia, aunque tras una colaboración evidente, acaba prescribiendo la lectura de esas imágenes con los pies de foto $\mathrm{y}$, con ello, se plantea la duda de si acaba otorgándose la autoría intelectual final $^{23}$, por un lado, o reivindicando una autoría descentrada, colaborati-

23 De forma acaso aún más contundente, Fontcuberta (2015) se pregunta: “¿Dónde pasa a residir, entonces, el mérito de la creación? La respuesta parece simple: en la capacidad de dotar a la imagen de intención y de sentido, en hacer que la imagen sea significativa" (53). 
va -sumada también a la de los hipotextos ya mencionados, procedentes de Tanizaki y Akutagawa-, por otro. Como advierte Fontcuberta (2016): “[...] la postfotografía rubrica la desmaterialización de la autoría al disolverse las nociones de originalidad y propiedad" (40). En cualquier caso, como se hace aquí también patente, y como sigue abogando el decálogo de la postfotografía, en su práctica suele imperar un espíritu lúdico, de juego compartido, en el que asoma también una crítica sobre los límites, la política y la ética del arte, algo que atañe también a la instancia lectora: "la noción de autoría basada en la individualidad y en el genio retrocede ante los proyectos en equipo de autoría compartida y no jerarquizada, ante la proliferación de obras colectivas e interactivas, pero, sobre todo, ante la concepción del público, ya no como mero receptor pasivo, sino como coautor" (55).

Una vez más, Bellatin experimenta con la imagen y sus límites y demuestra de forma clara que lo que le interesa es la exploración de la manera de contar y no lo que se cuenta, la forma y no la anécdota, el camino y no el fin, siguiendo su esquema particular de narración, que pone a prueba una y otra vez al lector y desplaza constantemente la frontera entre realidad y ficción, marcando la ambigüedad inmanente de lo que se consensua convencionalmente como verdad; de este modo, de hecho, se produce el desplazamiento de lo fáctico a lo plástico. El espejismo de la literatura per se.

Jugando con los aparentes referentes japoneses, situados en la superficie, Bellatin propone ahondar en lo puramente literario, más allá de los ejes espacio-temporales que, supuestamente, vinculan a un autor con sus referentes inmediatos. Por eso los dinamita desde dentro. Esto nos conduce a la reflexión inicial, sobre la posible pertenencia del autor al campo literario mexicano o peruano. Podría decirse que Bellatin sigue, a pesar de las abismales diferencias que los caracterizan, un camino paralelo de extraterritorialización al de los llamados narradores del crack, como Jorge Volpi (la Alemania nazi de En busca de Klingsor (1999), pero también la isla de Patmos, París o la antigua Unión Soviética, en No será la tierra (2006)), o el recientemente desaparecido Ignacio Padilla, de Amphytrion (2000) a La gruta del toscano (2006), por citar a los dos autores del grupo más conocidos fuera de México ${ }^{24}$; o ese otro excéntrico ya

24 El llamado crack puede leerse en paralelo, de algún modo, con el conocido McOndo, cuyas propuestas coinciden temporalmente, justo hacia el final del pasado siglo y principio de milenio. De forma muy sintética y esquemática, ambos grupos estaban constituidos por escritores que reivindicaban 
mencionado, Pablo Soler Frost, convertido, además, en personaje en las páginas de Bellatin ${ }^{25}$. Se diría que a los narradores mexicanos de las dos últimas décadas, tras la exploración que sus mayores realizaron del espacio rural, en la novela de la revolución mexicana y su liquidación en la maestría de Rulfo, así como del espacio urbano en la novela de la Onda, sólo les quedara la posibilidad de explorar otros ámbitos: se cambia de escenario, se trasladan las historias a otros lugares y a otras latitudes, como Centroeuropa u Oriente. Sin embargo, esta hipótesis no puede ser del todo confirmada, porque esta no es una característica exclusiva de la narrativa mexicana reciente. Autores como el ecuatoriano Leonardo Valencia (en las distintas versiones de La luna nómada (2004) o El libro flotante de Caytran Dölphin (2006)), el cubano Rolando Sánchez Mejías, con su fascinación por China, el boliviano Edmundo Paz Soldán y su desubicado Río Fugitivo (1998), o el guatemalteco Rodrigo Rey Rosa, con su afán viajero, entre otros muchos, optan por esa misma transterritorialización, aunque le den nombres diversos, como literatura errante o nómada. De alguna manera, con este cambio de espacio en la literatura hispanoamericana reciente, se da la vuelta al exotismo, se neutraliza la posible identificación nacional, y su reduccionismo, para extenderse en la abstracción que supone un espacio todavía otro, descontextualizado socio-históricamente, quedando así la construcción narrativa desnuda y a la intemperie. Tratando de romper las etiquetas y escapar del reducto de las literaturas nacionales, reivindicándose como parte de la literatura mundial, como bien postulara Jorge Luis Borges en su archicitado ensayo “El escritor argentino y la tradición”, publicado en Discusión (1932). En este sentido, Rodrigo Fresán, escritor hispano-venezolano-mexicanoargentino, creador de ese espacio de ficción móvil y cambiante en su narrativa que es Canciones Tristes -Sad Songs, Chansons Tristes, Traurige Lieder-, ha insistido en incansables ocasiones que "la patria de un autor es su biblioteca” (2002, s/p). Y podría añadirse, tal y como cierta vez dijera su viejo amigo Marcel Proust, que "cada artista parece ser el ciudadano de una patria desconocida".

el cosmopolitismo, aunque, en el primer caso, estaba formado solo por autores mexicanos, mientras que en la antología de Alberto Fuguet y Sergio Gómez participaron narradores transatlánticos, de distintos países de América Latina y también de España (cfr. Fuguet y Gómez 1996 y Chávez Castañeda, et al. 2004). 25 Del mismo modo que se convierte a sí mismo en personaje comparsa en Biografía ilustrada de Mishima (Bellatin 104), en la imagen 48, en un retrato con la leyenda o pie de foto donde se apunta "pareja de analistas que trabajó el caso Mishima", como bien ha sabido destacar G. Camenen (6). 
En esta dirección apunta Mario Bellatin, quien, en una entrevista, ante la pregunta sobre qué buscaba con la recreación de espacios y culturas diferentes, como la japonesa, respondió: “Esos juegos con ciertas retóricas de literaturas tradicionales son sólo un paso más para crear el universo sin tiempo y sin espacio que comencé a escribir desde mi primer libro" (Méndez s/p.). Acaso el texto de Shiki Nagaoka titulado con un kanji intraducible fuera, después de todo, su obra ideal. Simplemente, literatura.

\section{Bibliografía}

Aira, César. Varamo. Barcelona, Anagrama, 2002.

Akutagawa, Rynosuke, "La nariz". En Bellatin, M. Shiki Nagaoka: una nariz de ficción (Ed.). Buenos Aires, Sudamericana, 2001, pp. 87-94. [1915].

Aub, Max. Jusep Torres Campalans. México D. F., Tezontle, 1958.

Barthes, Roland. La cámara lúcida. Sobre la fotografía. Barcelona, Paidós, 1989 [1980].

Bellatin, Mario. Mujeres de sal. Lima, Lluvia, 1986.

_. Salón de belleza. Lima, Jaime Campodónico, 1994.

_. Damas chinas. México D. F., Síntoma Editores, 1998.

___. El jardín de la señora Murakami. Oto-no Murakami monogatari. México D. F., Tusquets, 2000.

. La escuela del dolor humano de Sechuán. México D. F., Tusquets, 2001.

. Shiki Nagaoka: una nariz de ficción. Buenos Aires, Sudamericana, 2001.

_. Flores. México D. F., Joaquín Mortiz, 2001.

. Jacobo el mutante. México D. F., Alfaguara, 2002.

_..Perros héroes. México D. F., Alfaguara, 2003.

. "Bola negra”. Pájaro transparente. Buenos Aires, Mansalva, 2006, pp. 59-74.

. El gran vidrio. Barcelona, Anagrama, 2007.

. Los fantasmas del masajista. Buenos Aires, Eterna Cadencia, 2009.

. Biografía ilustrada de Mishima. Buenos Aires, Entropía, 2009. 
(coord.). El arte de enseñar a escribir. México D. F., Fondo de Cultura Económica, 2010.

. El pasante de notario Murasaki Shikibu. Santiago de Chile, Cuneta, 2010.

. “¿Le gusta este jardín que es suyo? No deje que sus hijos lo destruyan". En Bellisco, Manuel, et al. (Eds.). Repensar la dramaturgia. Errancia y transformación. Murcia, Centro Párraga, 2011, pp. 57-73.

_. Obra reunida. Madrid, Alfaguara, 2013.

. Jacobo reloaded. México D. F., Sexto Piso, 2014.

. Retrato de Mussolini con familia. México D. F., Alfaguara, 2015.

___. Carta sobre los ciegos para uso de los que pueden ver. Madrid, Alfaguara, 2017.

Bellatin, Mario e Iturbide, Graciela. Demerol without Expiration Date/El baño de Frida Kahlo. México D. F., RM, 2008.

Bolaño, Roberto. La literatura nazi en América. Barcelona, Seix Barral, 1996.

Booth, Wayne C. The Rhetoric of Fiction. Chicago, The Chicago University Press, 1983. [1961].

Borges, Jorge Luis. “El escritor argentino y la tradición. Discusión (1932)”. Obras completas (1923-1949). Rolando Costa Picazo e Irma Zángara Eds.. Buenos Aires, Emecé, 2009, pp. 438-444.

___. "Historia universal de la infamia (1935)". Obras completas (19231949). Rolando Costa Picazo e Irma Zángara Eds. Buenos Aires, Emecé, 2009, pp. 589-684.

Calera-Grobet, Antonio. “Crónica del paseo. Entrevista con el escritor Mario Bellatin”. Tierra Adentro, no. 114, 2004, pp. 13-22.

Camenen, Gersende. "Les étranges texte-images de Mario Bellatin Fiction biographique et photographie". P. Edwards, V. Lavoie y J-P. Montier Coords. Photolittérature, littératie visuelle et nouvelles textualités. París, NYU, 2013, pp. 1-8 <http://phlit.org/ press $/ \mathrm{p}=1995>$.

Chávez Castañeda, Ricardo et al. Crack. Instrucciones de uso. México D. F., Mondadori, 2004.

Dávila, Lourdes. "Burla velada y fotografía en Shiki Nagaoka: una nariz de ficción”. La variable Bellatin. Navegador de lectura de una 
obra excéntrica. Julio Ortega y Lourdes Dávila Comp. Xalapa, Universidad Veracruzana, 2012, pp. 177-205.

Doumet, Christian. "De l'auteur représenté au frontispice de son libre". Portraits de l'écrivain contemporain. Orgs. J.-F. Louette y R.-Y. Roche. Seyssel, Champ Vallon, 2003, pp. 13-23.

Durand, Pascal. "De Nadar à Dornac. Hexis corporelle et figuration photographique de l'écrivain". COnTEXTES. Revue de sociologie de la littérature, no. 14, 2014, s/p <https://contextes.revues. org/5933>

Eco, Umberto. Seis paseos por los bosques narrativos. Barcelona, Lumen, 1996.

Escribano, Pedro. "Quien piensa, pierde. Entrevista con Mario Bellatin”. La República, no. 2 de junio de 2002, s/p.

Fontcuberta, Joan. El beso de Judas. Fotografía y verdad. Barcelona, Gustavo Gili, 2015.

_. Indiferencias fotográficas y ética de la imagen periodística. Barcelona, Gustavo Gili, 2011 [1997].

__. La furia de las imágenes. Notas sobre la postfotografía. Barcelona, Galaxia Gutenberg, 2016.

Fresán, Rodrigo. "La patria de un autor es su biblioteca”. El País, 9 marzo 2002, s/p https://elpais.com/diario/2002/03/09/babelia/1015634352_850215.html

Fuguet, Alberto y Gómez, Sergio (Eds.). McOndo. Barcelona, Mondadori, 1996.

Gras, Dunia. "Narradores no fiables, de Borges a Bolaño: del olvido como motor literario". D'Oublis et d'abandons. Notes sur l'Amérique Latine. Carla Fernandes Ed. Burdeos, Université BordeauxMontaigne, 2017, pp. 235-255.

. “La literatura nazi en América (1996), veinte años después: una lectura hemisférica compartida por El espíritu de la ciencia ficción (2016)". Roberto Bolaño: Estrella distante. En Juan Antonio González Fuentes y Dámaso López García Eds. Sevilla, Renacimiento, 2017, pp. 129-164.

Guerrero, Javier. Tecnologías del cuerpo. Exhibicionismo y visualidad en América Latina. Madrid-Frankfurt, Iberoamericana-Vervuert, 2014. 
Herrero-Olaizola, Alejandro. Narrativas híbridas: parodia y posmodernismo en la ficción contemporánea de las Américas. Madrid, Verbum, 2000.

Hirsch, Marianne. Family Frames. Photography Narrative and Postmemory. Cambridge, Harvard University Press, 2012 [1997].

Iturbide, Graciela. Juchitán de las mujeres, 1979-1989. México D. F., RM, 2010.

Laddaga, Reinaldo. Espectáculos de realidad. Ensayo sobre la narrativa latinoamericana de las últimas dos décadas. Rosario, Beatriz Viterbo, 2007.

López Alfonso, Francisco José. Mario Bellatin, el cuadernillo de las cosas difíciles de explicar. Alicante, Publicaciones de la Universidad de Alicante, 2015.

Martens, David y Reverseau, Anne. “Iconographies de l'écrivain au XXe siècle. Usages et enjeux: un portrait en pied". Image and narrative, vol. 4, no. 13, 2012, pp. 154-168.

Méndez, Juan Carlos. “Efecto Bellatin (entrevista)”. Caretas, no. 1707, 7 febrero 2002, s/p, <www.caretas.com.pe/2002/1707/secciones/cultural.phtml>.

Mochkofsky, Graciela. “Mexico's Literary Prankster Goes to War with His Publisher". The New Yorker, 23 diciembre 2015, <www.newyorker.com/contributors/graciela-mochkofsky>.

Monterroso, Augusto. Lo demás es silencio. Madrid, Cátedra, 2003 [1978].

Nabokov, Vladimir. Pale Fire: a Novel. Nueva York, Lancer Books, 1962.

Ortega, Julio y Lourdes Dávila (Comp.). La variable Bellatin. Navegador de lectura de una obra excéntrica. Xalapa, Universidad Veracruzana, 2012.

Paz Soldán, Edmundo. Río fugitivo. La Paz, Alfaguara, 1998.

Pérez-Fontdevila, Aina. Un común singular. Lecturas teóricas de la autoría literaria. Bellaterra, UAB, 2017.

Pérez-Fontdevila, Aina y Meri Torras (Eds.). Los papeles del autor/a. Marcos teóricos sobre la autoría literaria. Madrid, Arco Libros, 2016.

Pitois-Pallares, Véronique. El arte del fragmento: El Gran Vidrio de Mario Bellatin. Hermosillo, Universidad de Sonora, 2011. 
Plaza, Caridad. "Diálogo de la lengua. Mano a mano entre Jorge Volpi y Mario Bellatin". Quórum, no. 19, 2007, pp. 111-121.

Rodríguez Freire, Raúl. "El giro visual de la teoría”. Cuadernos de Teoría y Crítica, no. 2, Viña del Mar, 2016, pp. 7-14.

Ruthven, K. K. Faking Literature. Cambridge, Cambridge University Press, 2001.

Schwob, Marcel. Vidas imaginarias. Barcelona, Barral, 1972 [1896].

Steichen, Edward. "Ye, Fakers". Camerawork, no. 1, Nueva York, enero de 1903. Cit. en: Fontcuberta, Joan. Indiferencias fotográficas y ética de la imagen periodística. Barcelona, Gustavo Gili, 2011, pp. 24-25.

Tanizaki, Junichiro. Elogio de la sombra. Madrid, Siruela, 1994. (1933).

Tomas, David. "From the Photograph to Postphotographic Practice: Toward a Postoptical Ecology of the Eye". SubStance, no. 55, 1988, pp. 59-68.

Valencia, Leonardo. La luna nómada. Cádiz, Algaida, 2004.

_. El libro flotante de Caytran Dölphin. Madrid, Funambulista, 2006.

Walkowitz, Rebecca. Born Translated. The Contemporary Novel in an Age of World Literature. Nueva York, Columbia University Press, 2015. 